LA VOCACIÓN DE JESÚS... Y LA NUESTRA

Autor: Lorenzo Trujillo Díaz.

Rector del Seminario Mayor de Ciudad Real

\title{
DOI: https://doi.org/10.52039/seminarios.v47i160.969
}

\section{MEDITACIÓN CRISTOLÓGICA SOBRE LA LLAMADA ${ }^{1}$}

Si queremos entender algo de lo que significa la llamada o vocación, es imprescindible mirar a quien es origen, raíz y fundamento de la existencia creyente, Jesús. Fuera de él no tiene sentido la llamada, al menos en los términos de nuestra historia de fe. Contemplaremos la misión y vocación de Jesús y, a su luz, diremos algo sobre los mismos conceptos aplicados a nuestro caso. Hay más, muchos más, aspectos y dimensiones relativos a este tema sobre los que no trataremos. Este nos parece esencial.

${ }^{1}$ Para profundizar en la perspectiva que este artículo propone, cf. HANS URS VON BALTHASAR, Teodramática. 3.Las personas del drama. El hombre en Cristo. Ediciones Encuentro, Madrid 1993, pp.143-330. 


\section{COMO EN EL CIELO}

Carácter único de la vida de Jesús

La conducta de Jesús rompe las categorías de reconocimiento
1. Verbo, Hijo, Imagen del Padre. Con estos términos conocemos y nombramos el Quién de Jesús de Nazaret, su Persona. Si Jn.1, 14 ( $E l$ Verbo llegó a ser Carne), o Hb. 1, 1 (Resplandor de su gloria e impronta de su substancia) lo dicen con nitidez, todo el Nuevo Testamento es un ensayo para expresarlo, tanteando y descartando categorías religiosas que designaban al enviado de Dios: Mesías, Siervo, Profeta. Los seguidores de Jesús se vieron obligados a integrar en su lenguaje algo inaudito que, si bien antes se podía esquivar, a partir de la resurrección, experimentada y confesada, era imposible no toparse con ello: $E l$ carácter absolutamente único de la vida de Jesús. Toda vida humana, aun extraordinaria, se subsume en una serie de nombres comunes, que luego son individualizados -relativamente- con adjetivaciones: un maestro cristiano, un gran político socialista, un carismático moderno... Sólo en el caso del enamoramiento, saltan los tópicos y la persona amada es captada como única, como inefable. Es un momento maravilloso. Después, en alguna medida, la convivencia rompe el encantamiento y sólo el perdón a las limitaciones del otro consigue hacer brotar un amor con mayor dosis de comprensión que de admiración. La vida de Jesús va más allá de estos esquemas.

2. Sucedió ayer y sucede hoy. Jesús hacía un gesto profético y, de momento, la gente le identificaba como el Profeta. Pero ni siquiera esta individuación de la categoría era suficiente. Ante la autoridad que emanaba de su persona, se empieza a reconocer en él al Mesías (Hijo de David): la calificación queda otra vez corta. Su tarea, su actuación, su conducta, lejos de ayudar a situar a Jesús en la condición humana, rompen las categorías de reconocimiento y crean una perplejidad que atraviesa las épocas. No hay más remedio que preguntar por su quién: ¿Quién es este..? ¿Quién dice la gente que es...? (cf. Mc. 8, 27-30; Lc. 8, 25; Jn. 7, 25-52; 8). ¿Por qué? No basta decir qué cosa es este (profeta, mesías) porque en cada instante de su conducta está presente la totalidad, la integridad de su persona, convirtiendo esa conducta en signo que remite a un misterio. Lo mismo sucede cuando leemos los intentos actuales de aproximación a Jesús y las nuevas categorías propuestas: filósofo rural cínico, fariseo moderado y tolerante, aspirante al trono, profeta apocalíptico del fin del mundo, celota asaltante del Tem- 
plo, rabino carismático galileo, etc. Cuando uno lee estos conatos, encuentra, antes o después, una confesión de sus autores: que Jesús, siendo eso que cada cual sostiene, va más allá, desborda la categoría.

3. Los discípulos dieron un salto cualitativo en el conocimiento de Jesús. Le reconocieron como Alguien tan idéntico a sí mismo, que resulta únicamente identificado e identificable por y desde Dios. Alguien indecible con los tópicos normales. El cuarto evangelista confiesa habitualmente y sin pudor lo que con menos frecuencia, aunque no sin claridad, van confesando los demás. Jesús es El Hijo. Para conocerle no basta el vocabulario de Viejo Testamento y menos aun sirve el lenguaje de los mitos religiosos del paganismo ${ }^{2}$. Es preciso ser introducido en una familiaridad que rompe los límites de lo humano: "Bienaventurado eres Simón, hijo de Jonás, porque no te ha revelado esto la carne ni la sangre, sino mi Padre que está en los cielos" (Mt. 16, 17). “... Y nadie conoce bien al Hijo sino el Padre, ni al Padre le conoce bien sino el Hijo y aquel a quien el Hijo se lo quiera revelar" (Mt. 11, 27). "Nadie puede venir a mí, si el Padre que me ha enviado no lo atrae" (Jn. 6, 44). “... Como me conoce el Padre y yo conozco a mi Padre” (Jn. 10, 15; cf. 1, 18; 3, 11). Desde las coordenadas de la carne y de la sangre es imposible conocer a Jesús. Se hace precisa la entrada en esa familiaridad con la intimidad divina, sólo posible por la acción del Espíritu Santo. Únicamente la fe -los nuevos ojos de la fepuede hacer ver en las acciones de Jesús la presencia inmediata de Dios Padre y, desde este, contemplar la filiación absoluta de aquel. La fe capta una relación que es única y, en ella, la persona de Jesús como emisión del Amor paterno. La fe, en cierto sentido, consiste en recibir y confesar un lenguaje familiar respecto a Dios, dado por el Espíritu.

4. El término "hijo", con esa singularidad, no se aplica a Jesús por una reflexión ontológica (búsqueda de su naturaleza), sino que, en principio, es consecuencia de la excepcionalidad de su misión. Él es, personalmente, la emisión de la voluntad amorosa del mismo Dios para el hombre. Lo enseña Hebreos en su pequeña introducción temá-

2 En ellos, la designación con términos de parentesco responde al carácter simbólico del politeísmo y al intento de poner "orden" mediante teogonías que todos sabían irreales. Aquí el término "hijo" se aplica para aproximarse a la relación de obediencia absoluta entre Jesús de Nazaret (hombre históricamente real) y el Dios único al que él denominaba como Abbá. No tiene nada que ver. 
tica: "Muchas veces y de muchos modos habló Dios en el pasado a nuestros Padres por medio de los Profetas: en estos últimos tiempos nos ha hablado por medio de su Hijo". El mensajero siempre pierde una dosis del mensaje, mensaje de otro; siempre es hermeneuta parcial de otra voluntad, eco más o menos deformado de voz ajena; por eso vive la tensión entre su experiencia personal y la palabra que lleva, y

El Hijo habla del

Padre desde la intimidad única

La misión de Jesús mana de su centro personal siempre queda patente la diferencia entre lo que dice y lo que hace: el profeta habla en nombre de otro en la medida que le es dado. Mas el Hijo habla del Padre por el mismo hecho de serlo, desde una intimidad única: "A Dios nadie le ha visto jamás: el Hijo único, que está en el seno del Padre, él lo ha contado" (Jn. 1, 18). El caso de Jesús, según la experiencia de los discípulos tal como nos la trasmiten los evangelios canónicos, es muy distinto del de los profetas: la misión consiste en dejarse manifestar él mismo, o, de otro modo, aquí el mensaje es el mensajero. Consecuencia: el único término posible para designarle es el de Hijo. Como la designación no es metafórica en la intención de los creyentes, el proceso de reflexión que ocupó durante varios siglos a los grandes concilios orientales resulta natural y necesario. No es, en absoluto, un retroceso a las categorías helenistas ni ontologización indebida del evangelio.

5. La misión de Jesús no aparece como añadida, sino manando de su centro personal en una identificación total y en una entrega sin resquicios y desde siempre. Entonces, ¿cómo puede llamarse "misión"? ¿No es la misión una referencia necesaria a otros: enviantes, sujetos a quienes se envía...? Sólo en el caso de que la persona sea engendrada como misión, como emisión, solo en ese caso, es posible esta identidad. Hoy es frecuente oír que la creencia en la resurrección supuso el cambio de la religión de Jesús a la religión sobre Jesús, de la predicación del Reino de Dios a la proclamación de Jesús como contenido de la fe. Quienes, de un modo u otro, sostienen algo parecido, no han entrado en el alma del Nuevo Testamento. Eso que llaman la religión de Jesús no es, simplemente, la profesión del credo hebreo o la predicación de la llegada del Reino, sino la obediencia total, desde la inmanencia personal (Jn.1, 18), a Dios considerado como Abbá. Cuando los discípulos empiezan a intuir, sin duda bajo el influjo del Espíritu Santo, esta aparente paradoja, se produce la obscuridad y se abre la posibilidad de la luz. Jesús es único, el Único, el Hijo unigénito. Mar- 
cos lo proclama como noticia inicial, como título revelador: "Comienzo del Evangelio de Jesucristo, Hijo de Dios" (Mc.1, 1).

6. Los pensadores cristianos y los concilios no tuvieron más remedio que ir verbalizando lo que los testigos vieron, oyeron y palparon acerca del Verbo de la Vida $(1 \mathrm{Jn} .1,1)$. Engendrado al ser pronunciado, al ser dicho por el Padre en la eternidad. La eterna Palabra no designa a alguien, es ese alguien. Ese Alguien es Palabra de otro; pero Palabra total, o sea, la substancia de ese otro, su comunicación absoluta (homousios). El Verbo es persona al ser emitido y es misión siendo, simplemente, quien es. No es a quien se dirige la Palabra de Dios sino esa misma Palabra. Por tanto, es la "vocación" del Padre -sus entrañas de misericordia- puesta frente a sí como Persona divina, como Hijo. Este no necesita recibir una vocación porque ya es eternamente la Vocación: La Vocación de decir eternamente Abbá espirando todo el amor recibido, el Santo Espíritu. El Verbo no tiene ser al margen de esa 1lamada, de esa voz, de esa locución que es él mismo. Su Persona consiste en ser la Palabra, el término del decir divino. Por otro lado, al decir al Verbo, el Padre existe porque el Verbo, frente a Él, le realiza como Padre, el cual nada (nadie) es fuera de esto: Padre-del-Verbo. Todo su ser de Padre es dicho en la Palabra. La misión del Verbo, que es su Persona y su existencia, consiste en realizar al Padre, esto es, en darle gloria, en ser su Palabra.

7. Esta relación -Emisor y Verbo- sólo es posible en el Espíritu. En la mutua espiración del Amor personal, Hablante y Palabra se distancian y se entregan personalmente. La Palabra nace del Padre en el Espíritu; Espíritu que ella re-espira al Padre en obediencia amorosa y agradecida. Esta entrega eterna de la Palabra, este ser para decir al Origen, es el ser del Verbo. Por eso, en él, procesión, misión, vocación y persona, coinciden, son la misma cosa. La espiración es inefable y el Espíritu indecible; el Espíritu, sin embargo, es la vida de la Palabra, su resplandor y su gloria; vida, resplandor y gloria que ella devuelve al Padre arrebatada por el Amor.

\section{ASÍ EN LA TIERRA}

1. La encarnación no consiste en que el Verbo asuma una naturaleza humana, como si esta fuera añadida a la Persona divina tras ser

La Palabra no designa a Alguien, es ese Alguien

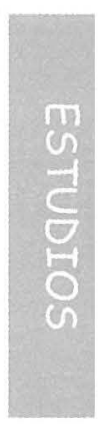


creada al margen de ella. Bajo esta terminología -legítima y necesaria si se entiende bien- podría subyacer una larvada y sutil confusión de naturaleza con cuerpo, y de persona con alma. Sería una forma de hablar no del todo adecuada con la dinámica del misterio, aunque serviría eficazmente para cerrar la puerta al siempre latente monofisismo.

Encarnación es plena realización de la creación en la persona del Verbo La encarnación es la realización de la generación eterna en el interior de la creación, y consecuentemente, la plena realización de la creación en la persona del Verbo. El Verbo no toma un cuerpo, ni asume una naturaleza, sino que llega a ser hombre histórico real (cuerpo y alma, espacio y tiempo, sensibilidad e inteligencia, afecto y querer): por la acción paterna de Dios que le entrega al mundo, por la intervención del Espíritu Santo que le hace real en la realidad creada, por la acogida de la Humanidad en María hija de Sión, y por una vida vivida y entregada día a día en obediencia por el mismo Verbo encarnando. La vida temporal de Jesús no acontece al margen del Verbo (o en paralelo), es su historia humana, la historia de su realización como Palabra de Dios en el interior de la convivencia humana. Y es, por eso, la historia de una misión que también en la tierra -como en el cieloconsiste en realizar (glorificar) al Padre en la salvación (realización) de sus hermanos. Vocación vocante: El Verbo pasa por la historia llamando, dando ser y misión filiales a quienes son atraidos o entregados por el Padre a Él.

2. La misión del Verbo entra y da comienzo en el tiempo con la vocación de María a entregarse a la Palabra: Hágase en mí según tu Palabra. El "fiat" inicial de la Creación se había interrumpido el día sexto abriendo un "descanso forzoso" para la acción divina. Ese día, Yavé había puesto en la existencia al varón y a la mujer, o sea, a la libertad humana. Fiel a su obra, Dios no podía plenificar lo creado si a su "fiat" originario no se unía, en desigual dúo cósmico, el "fiat" de la humanidad. El sábado fue el signo de la espera de Dios a la libertad humana y de la obediencia de esta a la libérrima gracia de Dios. Y el momento llega con María: Hágase. María es el Shabat de Israel personalizado y cumplido, el descanso de Dios dejando gestar a la humanidad y el descanso del hombre dejando actuar a Dios Padre mediante el Espíritu Santo. Jesús realizó su obra sanadora con preferencia en sábado - ¡El Hijo del Sábado!- porque él mismo era la Alianza esponsalicia entre Dios y la humanidad. La vocación sabática de María hace 
posible la misión del Verbo en el tiempo, su engendramiento carnal. María deja pasar, libremente, a través de su ser a la Palabra divina. La Hija de Sión, entretejida por la Palabra que a través de los siglos ha recibido Israel y que, en este caso particular, está libre de interferencias adamitas, es llamada por la misma Voz que engendra a la Palabra eterna. El nacimiento de Jesús es fruto de la existencia previa de María en el Verbo de Dios por la plenitud de gracia del Espíritu Santo.

3. Como es evidente si se da fe al relato lucano de la anunciación (Lc.1, 26-38) -virginidad aceptada y fecundada-, la relación de María con Jesús niño es la de una madre humana con su hijito, pero, también, posee un matiz único y fundamental: necesariamente María refiere su Jesús en todo momento al Padre, a Dios; de palabra, obra, pensamiento y expresión afectiva. Toda madre, para dar una identidad distinta a $s u$ hijo y no fundirlo y ahogarlo en su persona, necesita remitir el fruto de sus entrañas al otro responsable de su existencia. El reconocimiento del padre y por parte del padre, otorga al hijo esa distancia existencial respecto a la madre que le permite ser libre o, simplemente, ser. ¿A quién refiere María a su hijo sino a Dios? Jesús es fruto del Misterio y su madre vive en el Misterio que ha dado existencia al hijo amado. Al oír María la voz creadora de Dios, le ha percibido como Padre y Origen de un modo único. Percibiendo Jesús el tono (connotación, "retintín") con que María se dirigía a Dios y con que le enseñaba a llamarle "Abbá", la conciencia del niño nace y se desarrolla desde este punto radical: es el hijito de Dios, su padre único a quien debe absolutamente existencia, configuración y misión. También José colaboraría al nacimiento de esta conciencia humana refiriendo su paternidad adoptiva a la orden de Dios. La conciencia personal del Verbo encarnando se desarrolla a la vez que va siendo sabedor de su misión, y viceversa. Es lo que encierra el término "Abbá" en labios de Jesús.

4. Los relatos de la Infancia según Lucas nos presentan a María, acompañada por José, ofreciendo en el Templo a su hijo. El Templo es el lugar de la Presencia y, también, del sacrificio de adoración. José y María reconocen, como nadie anteriormente, la propiedad de Dios sobre el Hijo, el Consagrado por excelencia. Se trata del preludio del sacrificio -como profetiza el anciano Simeón- y, por tanto, del sacerdocio. Jesús no puede nacer ni morir al margen del Templo aunque su vida desborde el Lugar y lo rompa y lo abra. El autor del relato lucano

Maria refiere a Jesús como hijo del Padre, configuración y misión 
de la infancia, quizá un levita de Jerusalén, comprende la vida de Jesús como una consagración para la entrega, como una disposición sacerdotal que Dios mismo irá desvelando en cada momento histórico.

5. Pero este primer encuentro del Verbo humanado con el Templo, lugar de la Gloria, no agota el mensaje. Cuando el evangelista parece haber dicho todo, y cierra literariamente el pasaje con la vuelta a Nazaret (Así que cumplieron todas las cosas según la Ley del Señor, volvieron a Galilea, a su ciudad de Nazaret. El niño crecía y se fortalecía, llenándose de sabiduría; y la gracia de Dios estaba sobre él, ¡Fin del origen!), de pronto rompe la tranquila estancia en la aldea con una tensión inesperada: la peregrinación al Templo a los doce años. Si se trata de la celebración del barmitzvá de Jesús - aunque no está documentada la celebración de esta fiesta en aquella época, no resulta impensable en sí misma y menos desde la lectura del pasaje- la escena que Lucas describe sería de gran importancia teológica. La fiesta convierte al adolescente en hijo de la Alianza, hijo de la Ley, hijo de la Palabra. Cuando el rabino calla y el niño sigue cantando, solo, el Shema', el mandamiento de los mandamientos, en el caso de Jesús hemos de imaginar su alma arrebatada y su conciencia humana abismada en la Gloria. Se perdió en su ser íntimo y sus padres hubieron de recuperarlo para el lento tiempo humano de Nazaret, o sea, para la encarnación. También nosotros, espíritus-en-el-mundo, encarnaciones diminutivas, nos sentimos incómodos ante tanta espera y actuamos a veces como "patos apresurados". Todo proceso de incardinación en el mundo conlleva el sufrimiento íntimo de un sujeto espiritual (el Verbo en el caso de Jesús) al insertarse en el tiempo fragmentario. La adolescencia (¿eran Adán y Eva adolescentes despertando?), que es el tiempo de la autoexperiencia, es también el tiempo del rechazo del tiempo y el tiempo de la ansiedad cargada de urgencias. Sólo la obediencia salva al adolescente porque le resitúa en el tiempo. ¿No sabíais que yo debía estar en la casa de mi Padre? No se trata de un descubrimiento, ni de un inicio vocacional sino de una

Los padres son los pastores del tiempo para sus hijos evidencia íntima; basta comparar el pasaje con el de la llamada del niño Samuel en el Templo (1 Sm. 3). Para el adolescente era algo tan sencillo, tan evidente: ¿No sabíais...? ¡Vosotros debíais saber! Pero en la ignorancia de ellos hay una profunda sabiduría, la sabiduría de los sencillos: el valor del tiempo y de la espera. Los padres, también María y José, son los pastores del tiempo para sus hijos. A los que hacen de 
padres se les confía la administración del tiempo, porque el tiempo corresponde al Padre en exclusiva ("El Hijo no conoce el día ni la hora"). El niño debía volver a su hogar. La identidad entre su persona y su misión no hacía innecesaria la mediación; al contrario, la convertía en imprescindible para no confundir la Hora.

6. En el Jordán habló el Padre ante el profeta-notario. No se trata de un relato de vocación en el sentido que habitualmente usamos. Desde nuestra perspectiva, la vocación es siempre una gracia que irrumpe en la historia creando no sólo una discontinuidad externa sino una ruptura interna, un nombre nиеvo. Es lógico: en nuestro caso, Dios -aunque lo tuviera previsto desde el vientre materno- tiene que construir un sujeto dotado de libertad, es decir, no configurado personalmente pero sí abierto a la Voz, para que en el momento preciso pueda aceptar o rechazar la oferta. Desde nuestra experiencia, la historia de toda vocación es siempre una historia de apertura y de resistencia, de gozo y de dolor. Por eso, los relatos de vocación en la historia religiosa, cristiana y no cristiana, contienen dos partes: a) El desengaño de la antigua vida que empuja a buscar en la obscuridad, y b) la iluminación o conversión vocacional con el nombre nuevo de misión. En el caso de Jesús, contra todo pronóstico, la tentación llega después del relato "vocacional" y es un primer ejercicio del mismo, no su preámbulo. Y porque en el caso de Jesús no se trata de vocación en nuestro sentido sino de revelación de la persona-misión del Hijo, por eso es también continuación de ese engendramiento en la historia que es la encarnación; la paloma que desciende y el Nuevo Adán que emerge de las aguas convierten el relato en un "arjé" genesiaco. El Verbo va llegando a ser hombre o a realizar su Persona en el ámbito real de lo humano conforme se va entregando históricamente a la voluntad del Padre en el Espíritu mutuo. Históricamente hablando, en el Jordán empieza la misión de Jesús como Hombre Público (Nuevo Adán) de la historia de salvación. Pero no hay ruptura interior, no existe resistencia, no hay nombre nuevo. Es, simplemente, la Hora.

7. La llamada a los discípulos y la nominación específica de los Doce, nos muestran cómo la Palabra encarnada es vocación vocante, llamada que llama con su palabra pero también con su mera presencia. Todas las personas que aparecen en el Evangelio ven alterada su iden-
La Palabra llama con su sola presencia
En el Jordân comienza la misión de Jesús como hombre público de la historia de salvación tidad existencial por la presencia histórica de Jesús-prójimo. Cada uno 
recibe (la acoja o no) su misión en el plan del Padre; todos y cada uno juegan como mediaciones para que la Hora se vaya preparando y acercando, pero, al mismo tiempo, Jesús, la Palabra encarnada, con la presencia del Espíritu Santo, despierta la personalidad teológica de ellos y los convierte en coautores del Drama de la Salvación.

8. La mediación humana irá mostrando la Hora del Padre en cada momento. María, mediadora radical y necesaria en toda la encarnación, lo hará en Caná con ocasión de unas bodas. Cuando Jesús verifica la obediencia de María a la Palabra (haced lo que él os diga) entiende que lo que en principio era no-hora se ha convertido en Hora. Ya puede, debe, realizar el primer signo, signo de Alianza nupcial con el Pueblo. El Esposo ha llegado y los discípulos pueden creer en él. Igualmente será una mujer -sirofenicia y pagana- la que con su profunda humildad ("los perritos comen bajo la mesa las migajas de los niños", Mc. 7, 28), le indique que ha llegado la hora de ir a Jerusalén para cumplir la misión y abrir la mesa a los gentiles. Los gentiles que encuentran a Jesús dejan de ser propiamente gentiles (no-pueblo) y empiezan a participar de este carácter verbal o misionero (Mc. 7, 31-37; Mt. 8, 5-13; Jn. 4).

9. "Antes de la fiesta de la Pascua, sabiendo Jesús que había lle-

Jesús va a ser Palabra hasta caer en el abismo del silencio gado su hora de pasar de este mundo al Padre, habiendo amado a los suyos que estaban en el mundo, los amó hasta el extremo" (Jn. 13, 1). Así abre el cuarto evangelio el llamado Libro de la Gloria. Jesús va a vivir su vocación hasta el extremo: va a ser hijo hasta ponerse absolutamente en manos del Padre, va a ser Palabra hasta caer en el abismo del silencio cuando el Diciente calle: “ ¡Abbá, Padre!; todo es posible para ti; aparta de mí esta copa; pero no sea lo que yo quiero, sino lo que quieras tú" (Mc. 14, 36). El conjunto de Cena, Muerte y Resurrección muestra la plena realización humana de la Palabra divina. La vocación de Jesús a realizar su misión, o sea, su persona, en el mundo del pecado, se ha cumplido; su generación eterna ha entrado plenamente en el tiempo de esta creación. Ahora sí que se puede decir "el Verbo llegó a ser carne".

10. Deberíamos haber descrito otros pasos de la vida humana del Verbo. Lo importante es que, en cada hora de esa vida, se entrega la totalidad de la Persona. Por eso todos los tramos son "misterios", cada uno pleno y plenificante, todos mutuamente implicados, y no por la 
sucesión temporal sino por el sentido de signo de la plenitud personal que cada uno ofrece. Cada "misterio" de la vida del Señor es una llamada latente que se hace patente cuando, ante el acontecimiento presente, el Espíritu da a alguien muy determinado ojos para ver y corazón para sentir el amor de Jesús ante esta situación. Cada "misterio" está representado en alguna vocación específica realizada en la Iglesia. Si por vocación se entiende la llamada que rompe la continuidad íntima de una vida y pide su entrega en ese abismo de discontinuidad y de inseguridad, hay que decir que Jesús no tuvo vocación. Él fue la Vocación que, desde el Padre, entró en el mundo para ir despertando vocaciones y misiones personales que condujeran a la Historia hasta su meta, Él mismo.

\section{PARA NUESTRA SALVACIÓN}

1. Hemos sido creados en el Verbo. El amor del Padre por el Hijo engendrado, su contemplación rendida ante Él, se traduce en el acto de "regalar" al Hijo imágenes vivientes de su gloria y de su belleza, pequeñas "holografías" libres, cada una con un nombre propio. Iconos del Icono que repiten en infinitas perspectivas la riqueza interior del Hijo amado. Como los padres humanos, que no se cansan de hacer fotografías de todos los ángulos y momentos de sus hijos, Dios refleja en nuestro ser, a diminuta y variadísima escala, la belleza de su Verbo. Y viceversa: el amor del Hijo por el Padre, su adoración obediente, recibe con gratitud el regalo paterno y lo entrega con su propia entrega personal, como homenaje a quien es el Amor Fontal; desea el Hijo ardientemente "extender" la paternidad divina (";santificado tu Nombre!"), hacer al Padre el regalo de innumerables hijos que él acoge y realiza como hermanos. Dada su filiación única, ni siquiera podríamos existir si el Hijo no reconociera nuestra filiación acogiéndonos como hermanos queridos. El Espíritu de Amor entre Padre e Hijo hace reales, "tridimensionales", vivos, "en color", las imágenes creadas en la relación paterno-filial. Somos creados en el flujo y reflujo del Santo Amor entre Padre e Hijo. Proyectos de personas teologales, gestadas en el tiempo de la Gracia que es el tiempo de la encarnación del Verbo.

2. Pero el proyecto paterno-filial ha de ser recibido, vivido, aceptado por los sujetos creados en ese tiempo o existencia. Sujetos también 
de su propia realización, capaces de aceptar y de rechazar; libres, en una palabra. El ser humano ha gozado desde el comienzo de la facultad de salir de la corriente de Amor que es su hábitat nativo; ha podido pedir

Fuera de la relación con el Padre y el Hijo el hombre camina a la irrealidad la herencia y marcharse de la casa del Padre y de la compañía del Hijohermano. Fuera de la relación entre el Padre y el Hijo, el hombre camina a la irrealidad, a la autodestrucción, puesto que nada existe al margen de Dios. La encarnación del Verbo, en esta situación de pecado, es salvífica, realizadora, pero también redentora. Es una encarnación que violenta una situación de falsa autonomía y que por ello es violentada por la misma: la Cruz es inevitable históricamente hablando. El Bảutismo nos injerta en el misterio de Jesús, Verbo encarnado, en su muerte y resurrección, para que, mediante el amor crucificado, volvamos a la Realidad, ahora realizada plenamente por quien es su autor.

3. Si nuestro hábitat nativo es el mutuo Amor del Padre y el Hijo, la libertad que se nos concede como proyectos de personas en el Verbo, es libertad para realizarnos como verbos emitidos (misiones) por el Padre hacia Hijo y viceversa. Si Dios pudiera compararse al novelista creador de los personajes de una trama, habría que pensar en una historia donde esos personajes gozaran de la posibilidad de rebelarse contra el autor para intentar ser, cada uno, protagonista de $s u$ propio relato (¿Niebla, de Unamuno?). Pensemos en nuestro Cervantes: su criatura querida, su "hijo único", retrato verbal de una historia íntima de frustración asumida en tierna ironía, es sin duda don Quijote. Para destacar su imagen amable y estrambótica, para dibujar su nobleza de alma, por amor a él, el autor va creando personajes que ayudan a situar la vida del hidalgo y a desarrollar su historia; están al servicio del protagonista, pero, a la vez, en relación con ese protagonista encuentran su identidad entrañable y gloriosa; terminan siendo coprotagonistas muy individualizados y amados. Pensemos en el buen Sancho, en el ama y la sobrina, el ventero, Dulcinea, el barbero y el cura, el duque y la duquesa... y tantos otros. Pero, ¿y si Sancho, usando de la libertad de salirse de la obra, hubiera emprendido por su cuenta "La verdadera historia de un villano convertido en gobernador por méritos propios"? Habría estropeado la historia global en la cual su vida tenía sentido y realidad, y habría dificultado la realización de otros personajes. Esa es la tentación que sufre cada ser humano. Resulta difícil aceptar que sólo el Verbo es unigénito. 
4. Para poder hablar de vocación, en nuestro caso, la primera condición es habitar en la Casa del Padre, es decir, no haberse uno adueñado de su vida. La vocación de los humanos no se encuentra impresa y escondida en la "caja negra" de su intimidad subjetiva: no se conoce por introspección ni se realiza en la independencia. Está fuera de él, clamando en los sucesos de cada día y en algunos muy especialmente; aparece en la historia en el momento que Dios decide. Nuestra vocación radica en la libre y progresiva aceptación del "personaje" que debemos representar para entregarnos en él a la Salvación de otros y así ser realizados como personas. "Personaje" ofrecido por el Padre para hacernos colaboradores y partícipes de la historia de amor al mundo de su Hijo amado. "Personaje", en principio, extraño a nuestro ser inicial y provisorio. "Personaje" dado, pero abierto a la invención creativa siempre de cara al Protagonista. Ese proyecto de personas que somos, ha de pasar, libremente, por la aceptación de una misión en Cristo. Pero esa aceptación tiene su dinámica que conviene, al menos, esbozar:

4.1. Decíamos que para hablar de vocación era preciso habitar en la casa del Padre. Esto quiere decir: para oír la llamada es preciso abrir el corazón a la globalidad de "la novela", a su nudo fundamental, a su Autor y a su Protagonista, a sus personajes necesitados. Es fundamental conocer lo que Pablo denomina el Misterio (Ef. 3, 3-7): misterio de amor del Padre que nos ha entregado a su Hijo para que, por el Espíritu, accedamos a Él como hijos. O sea, es preciso tener la misma "inspiración" del Autor, concebir su misma idea para colaborar activa, creativamente, en la obra. Esa "inspiración" (Musa) es la presencia del Espíritu Santo en nuestros corazones: Él posibilita toda vocación en Cristo. Él abre los ojos de nuestra fe para que en un pequeño detalle reconozcamos la unidad y belleza del Amor y nos entusiasmemos hasta ir mucho más allá de lo pedido -ihasta el extremo!-; para que nos sintamos en nuestra casa y no veamos la misión como algo ajeno o impuesto; para que no seamos asalariados sino hijos en la "empresa familiar". Gracias a esta presencia podemos reconocer, en la vida externa, la invitación personalísima que empalma con los anhelos más profundos y casi siempre ignorados. Los sacramentos (Bautismo y Eucaristía radicalmente) y sus respectivas catequesis, son el ámbito donde la acción del Espíritu nos otorga la sensibilidad para el reconocimiento de la llamada como regalo presentido, esperado y agradecido de antemano. 
La vocación es siempre con-vocacion

¿Quizás sustitutos de los primeros invitados que se negaron?
5.2. Por otro lado, si la vocación es la oferta de un nombre (persona), en Cristo, al servicio de la historia de salvación, la vocación es siempre con-vocación. Nadie es llamado sin relación a las restantes llamadas; ninguna llamada, fuera de la del Hijo es absoluta. Esto quiere decir que más de una llamada depende de la aceptación o rechazo de otras llamadas. ¿Habría sido llamado Matías al apostolado de los Doce sin la defección de Judas? ¡Y esta pudo no darse! Perdón por la comparación, pero a veces pienso en Dios como un entrenador de fútbol que va sacando del banquillo jugadores en los que no pensó al organizar el equipo inicial; las lesiones, el cansancio de los "titulares", circunstancias variadas, pueden obligar al entrenador a poner en juego a deportistas no programados o a pedirles tareas para las que no eran adecuados en principio: ¡cuántas veces hemos visto ponerse a un delantero la malla de portero y hacer incluso alguna parada de mérito! Me pregunto en ocasiones: ¿cuántos habremos sido llamados en Cristo Jesús porque los "titulares" fallaron? ¿Cuántos estaremos jugando en puestos para los que en principio no fuimos pensados porque otras libertades han alterado el plan? ¿Habrá vocaciones a "hacer lo que se pueda" cuando no lo hace quien puede? ¿No se puede y se debe leer vocacionalmente el pasaje de los invitados que se negaron, y de los mendigos finalmente introducidos al banquete? Pero también en sentido contrario: ¡cuántas vocaciones posibilita una vocación aceptada y realizada! Lo vemos todos los días en las familias, ministerios, etc. El santo facilita a Dios la llamada a otros, hasta "sonsaca" de Dios llamadas "nuevas": ¡admirable el caso de los fundadores! Ya sé que Dios lo sabe todo y nunca es sorprendido. Pero estos antropomorfismos, ¿no tiene mucho de verdad si se piensan con mesura? Yo creo en la "mano izquierda de Dios" - esos caminos que no son nuestros caminos y esos renglones enderezados por la escritura divina-, en un mundo entretejido por decisiones libres y no siempre obedientes.

5.3. Abundando en el tema: ¿no habrá, incluso, "no-vocaciones" que sean vocaciones reales, auténticas vocaciones teologales sin "título" humano? La vocación no se justifica ni por la tarea inmediata ni por el aprecio o valoración social. Pienso ahora en personas que parecen no tener misión en la vida, "excedentes de cupo" para quienes miden las vidas por su utilidad inmediata: ¿no tendrán la misión de necesitar a otros y despertarlos a la caridad, o de soportar cargas que el 
"titulado" no alcanza a soportar? ¿Cuántos cirineos han dado su vida para que el protagonista pudiera llegar a la última escena? Los minusválidos, disminuidos, subnormales, ¿no han ido despertando en la humanidad una afectividad que desborda la justicia afectiva? O las antiguas "titas", solteronas que vivían en el hogar de la hermana y atendían a los abuelos, a los hijos..., sin ningún derecho sobre nadie, ¿no serán realizadas como madres de madres en la resurrección? ¿No recibirán allí la gloria de una maternidad que aquí ejercieron sin gloria y sin propiedad? O posibles vocaciones "fracasadas": ¿no recibirán, a veces, quienes abandonan una vocación, la vocación de ejercer la nueva misión como servicio indirecto a la antaño abandonada? ¡Hasta en el fracaso vocacional puede haber una hermosa vocación al servicio de la salvación en Cristo! Son vocaciones "in pectore" que serán dadas a conocer al término del camino. ¡Es tan grandioso, tan bello, tan complejo, tan misterioso, tan libre, tan lleno de amor, el plan de Dios realizado en el Verbo por el Espíritu!

6. Nuestra vocación es, por lo tanto, la misión ofrecida cuando ya somos algo: sujetos a la espera dotados de libertad. Tiene algo de injerto $\mathrm{y}$, como tal, puede generar en mayor o menor grado un cierto rechazo. Dios nos ofrece una misión al servicio del Hijo (La Misión). El resultado final de su aceptación es la configuración del sujeto libre como persona para la eternidad en Cristo Jesús resucitado. Los mártires, las vírgenes, los confesores de la fe, los fundadores, los pobres de espíritu, los misericordiosos, los pacificadores, los luchadores en pro de la justicia, no optaron por ser lo que fueron; fueron sorprendidos por la gracia y se dejaron seducir y conducir "a donde no querían". Es imposible en este momento contrastar nuestras prácticas pastorales con lo hasta aquí expuesto; me limito a expresar una convicción: la única pastoral vocacional posible consiste en desarrollar esa disposición filial apasionada, presta a recibir la llamada y a obedecer al envío. Una comunidad bautismal (parroquia, asociación, movimiento) que no viva en sus miembros esta disposición a obedecer, a levantarse ante la invitación para decir "aquí estoy", es muy dudoso que tenga en su seno al Espíritu Santo. Una comunidad bautismal que se limite a educar en valores genéricos de cristianismo anónimo conviene que se bautice de verdad en el Verbo de Dios y deje que el Espíritu Santo expulse a los malos espíritus de la opción ilusoria que falsifican la vida y la vacían de realidad teologal.

Dios nos ofrece una misión al servicio del Hijo 